\title{
ИССЛЕДОВАНИЕ АДАПТАЦИИ СТУДЕНТОВ ПЕДАГОГИЧЕСКОГО ВУЗА К КОГНИТИВНЫМ НАГРУЗКАМ В ПРОЦЕССЕ ОБУЧЕНИЯ
}

\section{RESEARCH OF ADAPTATION \\ OF PEDAGOGICAL UNIVERSITY \\ STUDENTS TO COGNITIVE LOADS IN THE PROCESS OF LEARNING}

\author{
Lyu. Sorokina \\ L. Buynov \\ A. Shangin \\ A. Krasnov \\ L. Syromyatnikova
}

Summary: Intensive cognitive loads, short training periods, changing requirements for the level of competence of graduates, often lead to a breakdown of the adaptive mechanisms of the student's body, which invariably leads to a decrease in the quality of educational results. The aim of the work was to study and analyze the triggers of adaptation mechanisms in students in the process of cognitive loads. The results of the study made it possible to determine the peculiarities of adaptation of students of a pedagogical university to cognitive loads, which determine the educational process as a stress-generating factor and equalize it in terms of energy consumption with physical activity. Thus, in order to preserve the health of students in the learning process, methods and technologies for correcting the functional state should be applied, which will balance the processes in the autonomic nervous system, thus avoiding the launch of adaptation mechanisms.

Keywords: education, adaptation, students, health.
Сорокина Людмила Александровна К.п.н., ФГБОУ ВО «Российский государственный педагогический университет им. А.И. Герцена»,

Санкт-Петербург

lux-86@mail.ru

Буйнов Леонид Геннадьевич

Д.м.н., профессор, ФГБОУ ВО «Российский государственный педагогический университет им. А.И. Герцена»,

Санкт-Петербург

buynoff@yandex.ru

Шангин Андрей Борисович

Д.м.н., профессор, ФГБОУ ВО «Российский государственный педагогический университет им. А.И. Гериена»,

Санкт-Петербург

andrej-shangin@yandex.ru

Краснов Алексей Александрович

Д.м.н., дочент, ФГБОУ ВО «РГПУ им. А.И. Герцена»,

Санкт-Петербург

dr.krasnov_28@mail.ru

Сыромятникова Лилия Ивановна

К.п.н., дочент, ФГБОУ ВО «Российский государственный педагогический университет им. А.И. Герцена»,

Санкт-Петербург

liliadok@yandex.ru

Аннотация: Интенсивные когнитивные нагрузки, сжатые сроки обучения, изменение требований к уровню компетентности выпускаемых специалистов, зачастую приводят к срыву адаптационных механизмов организма обучающегося человека, что неизменно ведет к снижению качества образовательных результатов. Целью работы явились исследование и анализ запусков механизмов адаптации у студентов в процессе когнитивных нагрузок. Результаты исследования позволили определить особенности адаптации студентов педагогического ВУЗа к когнитивным нагрузкам, которые обуславливают образовательный процесс как стрессогенный фактор и уравнивают его по энергозатратности с физическими нагрузками. Таким образом, для сохранения здоровья студентов в процессе обучения должны быть применены методики и технологии коррекции функционального состояния, которые позволят сбалансировать процессы в вегетативной нервной системе, позволив избежать запуска механизмов адаптации.

Ключевые слова: образование, адаптация, студенты, здоровье.

фундаментальная основа развития человеческого общества, повышения его интеллектуального и культурного потенциала.

Необходимость непрерывного обучения человека на сегодняшний день является основным условием его успешной социализации. Образовательные учрежде- 
ния, такие как школа, средние профессиональные или высшие образовательные учреждения перестают быть конечным этапом в получении знаний для человека. Постдипломное образование, переквалификация, различные профессиональные курсы и тренинги - это средства поддержания высокой степени компетентности специалистов на местах в условиях научно-технического прогресса и глобализации.

Образование сегодня рассматривается как феномен, изменяющийся под воздействием внешних и внутренних факторов окружающей его социальной среды. Смена образовательной парадигмы в контексте гуманизации и гуманитаризации образования нацелила педагогическое сообщество на взаимодействие между преподавателем и обучающимся по средствам создания адаптивной образовательной среды. Данный формат социально-педагогической системы позволяется учитывать, в том числе, индивидуальные особенности личности: психологические, физиологические, этнические и т.д. Таким образом, на первый план выходит проблема взаимодействия систем: образовательной и организма человека, что ведет к пересмотру догмы о согласованном взаимодействии педагога и обучающегося как компонентов в сложном механизме образовательной системы, которые a priori подходят друг другу [1,2,3].

Интенсивные когнитивные нагрузки, сжатые сроки обучения, изменение требований к уровню компетентности выпускаемых специалистов, зачастую приводят к срыву адаптационных механизмов организма обучающегося человека, что неизменно ведет к снижению качества образовательных результатов. В обозначенном контексте исследование адаптации участников образовательного процесса к когнитивным нагрузкам представляется актуальным научным направлением, позволяющим решить ряд фундаментальных задач здоровьесберегающего образования $[2,4,5]$.

Таким образом, целью работы явились исследование и анализ запусков механизмов адаптации у студентов в процессе когнитивных нагрузок.

Гипотезой исследования выступило предположение о том, что когнитивные нагрузки в процессе обучения запускают механизмы адаптации, реперной точкой которых будет являться изменение уровня глюкозы в крови респондентов.

\section{Материалы и методы}

Для подтверждения гипотезы о необходимости успешной адаптации участников образовательного процесса к когнитивным нагрузкам на кафедре медико-валеологических дисциплин в рамках обучения по курсу «Диагностика и коррекция функционального состояния обучающихся» было проведено инициативное исследование, для которого были отобраны 36 здоровых добровольцев в возрасте 19-21 года, не разделенные по гендерному признаку. Отбор добровольцев проводился с учетом первоначального пакета исследований, методики и критерии отбора представлены в таблице 1.

Таблица 1.

Первоначальный пакет исследований для определения критериальной годности респондентов к основному исследованию

\begin{tabular}{|c|c|c|}
\hline №ח/п & Методика & $\begin{array}{c}\text { Критерий годности } \\
\text { к исследованию }\end{array}$ \\
\hline 1 & 2 & 3 \\
\hline 1 & Индекс массы тела & $18,5-24,9$ \\
\hline 2 & $\begin{array}{l}\text { Жировая масса, нормированная } \\
\text { по росту }\end{array}$ & $\begin{array}{l}\text { M. } 18-20 \%, \\
\text { Ж. } 20-27 \%\end{array}$ \\
\hline 3 & Артериальное давление, мм.рт.ст. & $120 / 70 \pm 10$ \\
\hline 4 & Пульс & $70 \pm 4$ \\
\hline 5 & Электрокардиограмма & норма \\
\hline 6 & Спирометрия & норма \\
\hline 7 & $\begin{array}{l}\text { Нервно-психическая устойчивость: } \\
\text { многоуровневый личностный опросник } \\
\text { «Адаптивность» }\end{array}$ & 1,2 группа \\
\hline 8 & Тест на IQ Азенка & 100-120 баллов \\
\hline
\end{tabular}

Все участники были извещены о ходе исследования и его структуре, и дали добровольное информированное согласие на его проведение, в том числе, на самостоятельный замер уровня глюкозы с использованием бытового глюкометра.

Объем основного исследования включал в себя следующие методики: - артериальное давление систолическое, мм.рт.ст.; - пульс, уд/мин.; - тремор, баллы; - гипергидроз, баллы; частота дыхания дц/мин.; - простая сенсомоторная реакция, мсек.; - самочувствие, баллы; -активность, баллы; - настроение, баллы; - общее настроение, норм. фактор; - эмоциональное поведение, норм. фактор; - текущее состояние, норм. фактор; - тревожность, норм. фактор.

Артериальное давление и пульс измерялись тонометром; тремор, гипергидроз и частота дыхания измерялись с использованием прибора Физиолог-М; простая сенсомоторная реакция на световой раздражитель и показатели теста Люшера (общее настроение, эмоциональное поведение, текущее состояние и тревожность) с использованием АПК «Здоровье-экспресс»; методика САН (самочувствие, активность, настроение) проводилась с использованием типовых бланков.

Основным маркером, демонстрирующим запуск механизмов адаптации, в экспериментальном иссле- 
довании являлся уровень глюкозы в крови, измерение которого проводилось с использованием аппарата One Touch Verio Pro + каждым участником самостоятельно.

Исследование имело следующий дизайн: респонденты приходили в 10.00 не позднее 2 часов от момента завтрака, который должны были составлять преимущественно сложные углеводы. Первоначально проводился замер уровня глюкозы, данные фиксировались в протоколе исследования, затем проводилась диагностика физиологических и психологических показателей в соответствии с протоколом исследования. После чего респонденты были поделены на три равные группы путем генерации случайной выборки. Таким образом были сгенерированы две экспериментальных и одна контрольная, численностью 12 человек каждая. Экспериментальная группа 1 в течение 45 минут выполняла упражнения низкой степени интенсивности на велотренажере и 15 минут отдыхала. Экспериментальная группа 2 в течение 1 часа выполняла интенсивные умственные нагрузки: тест структуры интеллекта Амтхауэра, состоящий из 9 субътестов с ограниченным временем их выполнения. Контрольная группа 3 в течение 1 часа занималась интернет-серфингом (просмотром различной информации в сети Интернет).

Нагрузка распределялась из расчёта расходования порядка 450-490 кДж энергии. Каждые 15 минут участ- никами эксперимента проводился замер уровня глюкозы. По истечении 1 часа было проведено исследование в первоначальном объеме.

\section{Результаты}

Результаты проведенного исследования представлены в таблице 2.

Достоверно изменились следующие показатели функционального состояния обследуемых:

В экспериментальной группе 1 повысились: тремор, гипергидроз, скорость простой сенсомоторной реакции на свет, что свойственно для периода восстановления после физической нагрузки.

В экспериментальной группе 2 повысились: артериальное давление, пульс, гипергидроз, тремор и частота дыхания, что указывает на чрезмерное проявление вегетативных реакций нервной системы. Повысилась скорость простой сенсомоторной реакции на свет, снизились показатели самочувствия и активности, что указывает на снижение нервно-психической устойчивости.

В экспериментальной группе 3 повысилась тревожность, которая указывает на характер влияния просмотра информации в сети Интернет.

Таблица 2.

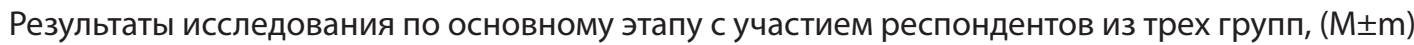

\begin{tabular}{|c|c|c|c|c|c|c|c|}
\hline \multirow[t]{2}{*}{ № ח/п } & \multirow[t]{2}{*}{ Методики } & \multicolumn{3}{|c|}{$\begin{array}{c}\text { Д0 } \\
(\mathrm{M} \pm \mathrm{m}) \\
\end{array}$} & \multicolumn{3}{|c|}{$\begin{array}{c}\text { После } \\
(\mathrm{M} \pm \mathrm{m}) \\
\end{array}$} \\
\hline & & $\ni 1$ & $\ni 2$ & K1 & Э1 & Э2 & K1 \\
\hline 1 & 2 & 3 & 4 & 5 & 6 & 7 & 8 \\
\hline 1 & $\begin{array}{l}\text { Артериальное давление } \\
\text { систолическое, мм.рт.ст. }\end{array}$ & $113,3 \pm 6,6$ & $115,5 \pm 6,8$ & $118,2 \pm 6,7$ & $114,6 \pm 6,7$ & $135,8 \pm 7,8 *$ & $115,3 \pm 6,1$ \\
\hline 2 & Пульс, уд/мин & $69,4 \pm 1,2$ & $71,1 \pm 1,8$ & $69,9 \pm 1,4$ & $71,2 \pm 1,5$ & $81,7 \pm 2,9 *$ & $70,4 \pm 1,3$ \\
\hline 3 & Тремор, баллы & $1,1 \pm 0,1$ & $1,3 \pm 0,2$ & $1,1 \pm 0,1$ & $1,8 \pm 0,4 *$ & $1,9 \pm 0,6 *$ & $1,1 \pm 0,2$ \\
\hline 4 & Гипергидроз, баллы & $1,3 \pm 0,5$ & $1,5 \pm 0,3$ & $1,4 \pm 0,3$ & $2,1 \pm 0,7 *$ & $2,3 \pm 0,5 *$ & $1,3 \pm 0,2$ \\
\hline 5 & Частота дыхания дц/мин & $17,1 \pm 2,1$ & $17,6 \pm 1,9$ & $17,9 \pm 2,2$ & $17,2 \pm 2,8$ & $22,8 \pm 2,9 *$ & $17,7 \pm 2,2$ \\
\hline 6 & ПСМР, мсек. & $305 \pm 18,3$ & $307 \pm 19,5$ & $303 \pm 18,9$ & $405 \pm 19,1^{*}$ & $407 \pm 19,6^{*}$ & $320 \pm 18,9$ \\
\hline 7 & Самочувствие, баллы & $5,1 \pm 0,3$ & $4,9 \pm 0,3$ & $4,7 \pm 0,4$ & $5,3 \pm 0,3$ & $4,1 \pm 0,4 *$ & $5,1 \pm 0,1$ \\
\hline 8 & Активность, баллы & $5,2 \pm 0,2$ & $5,1 \pm 0,1$ & $5,2 \pm 0,1$ & $5,1 \pm 0,3$ & $4,3 \pm 0,2 *$ & $5,3 \pm 0,2$ \\
\hline 9 & Настроение, баллы & $4,9 \pm 0,4$ & $4,8 \pm 0,3$ & $5,1 \pm 0,1$ & $5,2 \pm 0,1$ & $4,9 \pm 0,3$ & $5,2 \pm 0,1$ \\
\hline 10 & $\begin{array}{c}\text { Общее настроение, норм. } \\
\text { фактор }\end{array}$ & $0,3 \pm 0,1$ & $0,4 \pm 0,1$ & $0,2 \pm 0,1$ & $0,1 \pm 0,1$ & $0,3 \pm 0,2$ & $0,1 \pm 0,1$ \\
\hline 11 & $\begin{array}{c}\text { Эмоциональное поведение, } \\
\text { норм. фактор }\end{array}$ & $0,4 \pm 0,2$ & $0,2 \pm 0,1$ & $0,3 \pm 0,2$ & $0,3 \pm 0,2$ & $0,3 \pm 0,2$ & $0,2 \pm 0,1$ \\
\hline 12 & $\begin{array}{c}\text { Текущее состояние, норм. } \\
\text { фактор }\end{array}$ & $0,2 \pm 0,1$ & $0,1 \pm 0,1$ & $0,1 \pm 0,1$ & $0,5 \pm 0,2$ & $0,4 \pm 0,2$ & $0,1 \pm 0,1$ \\
\hline 13 & Тревожность, норм. фактор & $0,3 \pm 0,2$ & $0,2 \pm 0,1$ & $0,2 \pm 0,2$ & $0,1 \pm 0,1$ & $0,4 \pm 0,1$ & $0,7 \pm 0,1 *$ \\
\hline
\end{tabular}

Примечание. Знаком * обозначено достоверное изменение показателя у групп при $p \leq 0,05$ 
Графнк 1.

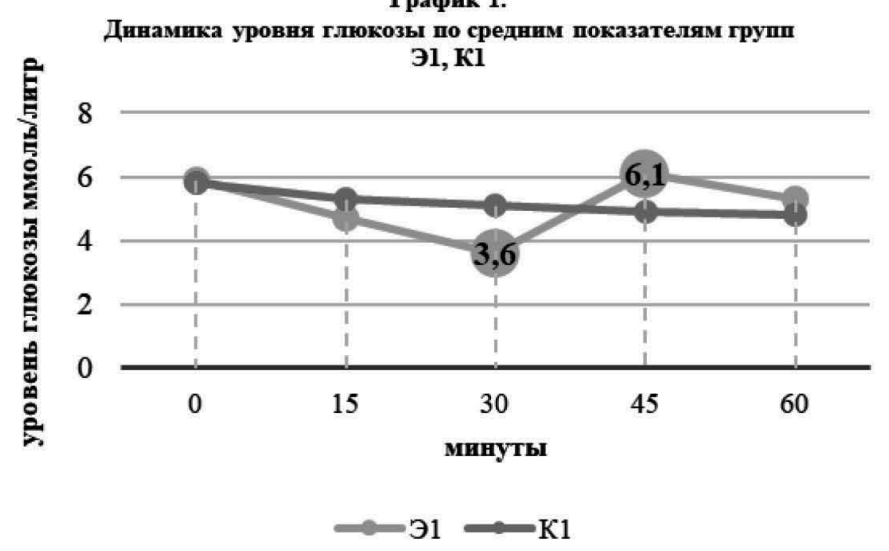

Для установления точки запуска адаптационных механизмов использовалась кривая уровня глюкозы во всех трех группах.

На графиках 1,2 можно наблюдать точку запуска механизма адаптации, при котором, в результате интенсивного расходования глюкозы организмом происходит ее спад до критического уровня, а затем начинает активно выделяться гликоген для стабилизации функционального состояния организма. У экспериментальных групп 1 и 2 запуск данного механизма адаптации произошел с 30 по 45 минуту исследования, у контрольной группы 1 точка запуска данного механизма адаптации не наблюдалась.

\section{Обсужмение}

Многочисленные исследования подтверждают тот факт, что сам по себе интеллектуальный труд наименее энергозатратен по сравнению с трудом физическим, однако в условиях интенсивной когнитивной работы при ограниченных временных условиях, выброс стрессовых гормонов, смещая баланс в вегетативной нервной системе в сторону симпатики, увеличивает энергозатраты организма в разы $[6,7,8]$. Таким образом, обучение является определенным стрессогенным

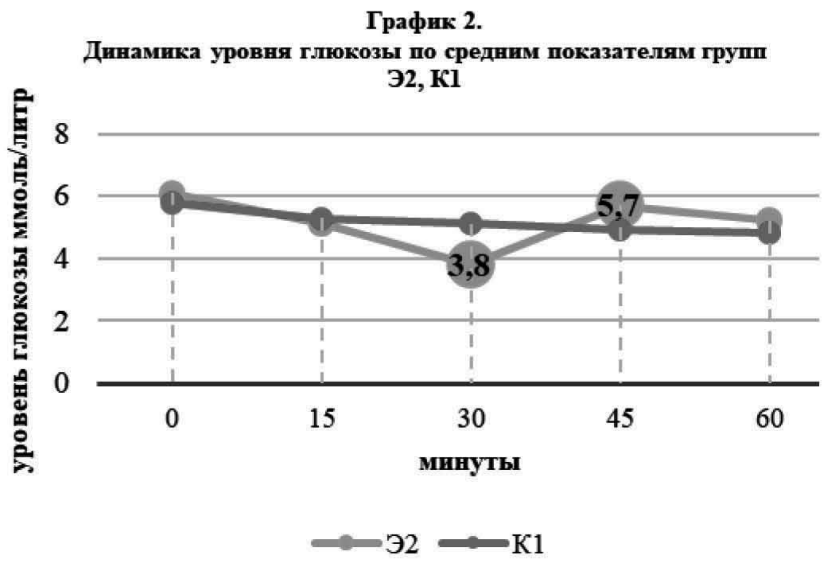

фактором для организма человека, существование в таких условиях может вести к стойкой реакции активации, риску развития различных психосоматических расстройств $[9,10]$. Это подтверждается результатами проведенного исследования и сравнительным анализом между группами. Так, студенты экспериментальной группы 2, выполняющие когнитивные нагрузки, имели изменения в наибольшем числе показателей, нежели респонденты двух других групп. Помимо этого, запуск механизмов адаптации, реперной точкой которых было выбрано изменение в кривой глюкозы указывает на соразмерность энергозарат при физических и когнитивных нагрузках.

\section{Выво $\Delta ы$}

1. Особенности адаптации студентов педагогического ВУЗа к когнитивным нагрузкам обуславливают образовательный процесс как стрессогенный фактор и уравнивают его по энергозатратности с физическими нагрузками.

2. Для сохранения здоровья студентов в процессе обучения должны быть применены методики и технологии коррекции функционального состояния, которые позволят сбалансировать процессы в вегетативной нервной системе, позволив избежать запуска механизмов адаптации.

\section{ЛИТЕРАТУРА}

1. Анохин П.К. Кибернетика функциональных систем: избранные труды. Издательство «Медицина», М., 1998: 400.

2. Бахтин Ю.К., Буйнов Л.Г., Макарова Л.П., Плахов Н.Н. Валеология - наука о здоровье, основа формирования здорового образа жизни. В кн.: Материаль IX Международной научно-практической конференции «Здоровьесберегающее образование - залог безопасной жизнедеятельности молодёжи: проблемы и пути решения». Челябинск; 2016: $19-28$.

3. Суворова А.В., Якубова И.Ш., Чернякина Т.С. Динамика показателей состояния здоровья детей и подростков Санкт-Петербурга за 20-летний период. Гигиена и санитария. 2017; 4: 332 - 338.

4. Трапезникова М.В., Савкин В.В. Мониторинг и прогнозирование психофизиологического статуса и успеваемости студенток 1-2 курсов медицинского вуза. Гигиена и санитария. 2015; 1: $104-108$. 
5. Судаков К.В. Нормальная физиология. Учебник для студентов медицинских ВУЗов. Издательство «Медицинское информационное агентство», СПб, 2006: 718.

6. Розова В.В. Современные аспекты психофизиологической адаптации студентов-первокурсников к обучению в вузе (на примере Тихоокеанского государственного медицинского университета). Морская медицина.2017; 2:59- 63.

7. Картышева С.И., Попова 0.А., Грошева Е.С. Самооценка здоровья и образа жизни студентов педагогического университета. Гигиена и санитария. 2015; $94(9): 18-20$.

8. Попов В.И., Мелихова Е.П. Изучение и методология исследования качества жизни студентов. Гигиена и санитария. 2016; 95 (9): 879 - 884.

9. Ермакова Н.А., Мельниченко П.И., Прохоров Н.И. с соавт. Образ жизни и здоровье студентов. Гигиена и санитария. 2016; 95 (6): 558 - 563.

10. Онищенко Г.Г. Санитарно-эпидемиологическое благополучие детей и подростков: состояние и пути решения проблем. Гигиена и санитария. 2007; 4:53 - 58.

\section{๑ Сорокина Людмила Александровна (lux-86@mail.ru), Буйнов Леонид Геннадьевич (buynoff@yandex.ru), \\ Шангин Андрей Борисович (andrej-shangin@yandex.ru ), Краснов Алексей Александрович (dr.krasnov_28@mail.ru), Сыромятникова Лилия Ивановна (liliadok@yandex.ru).}

Журнал «Современная наука: актуальные проблемы теории и практики»

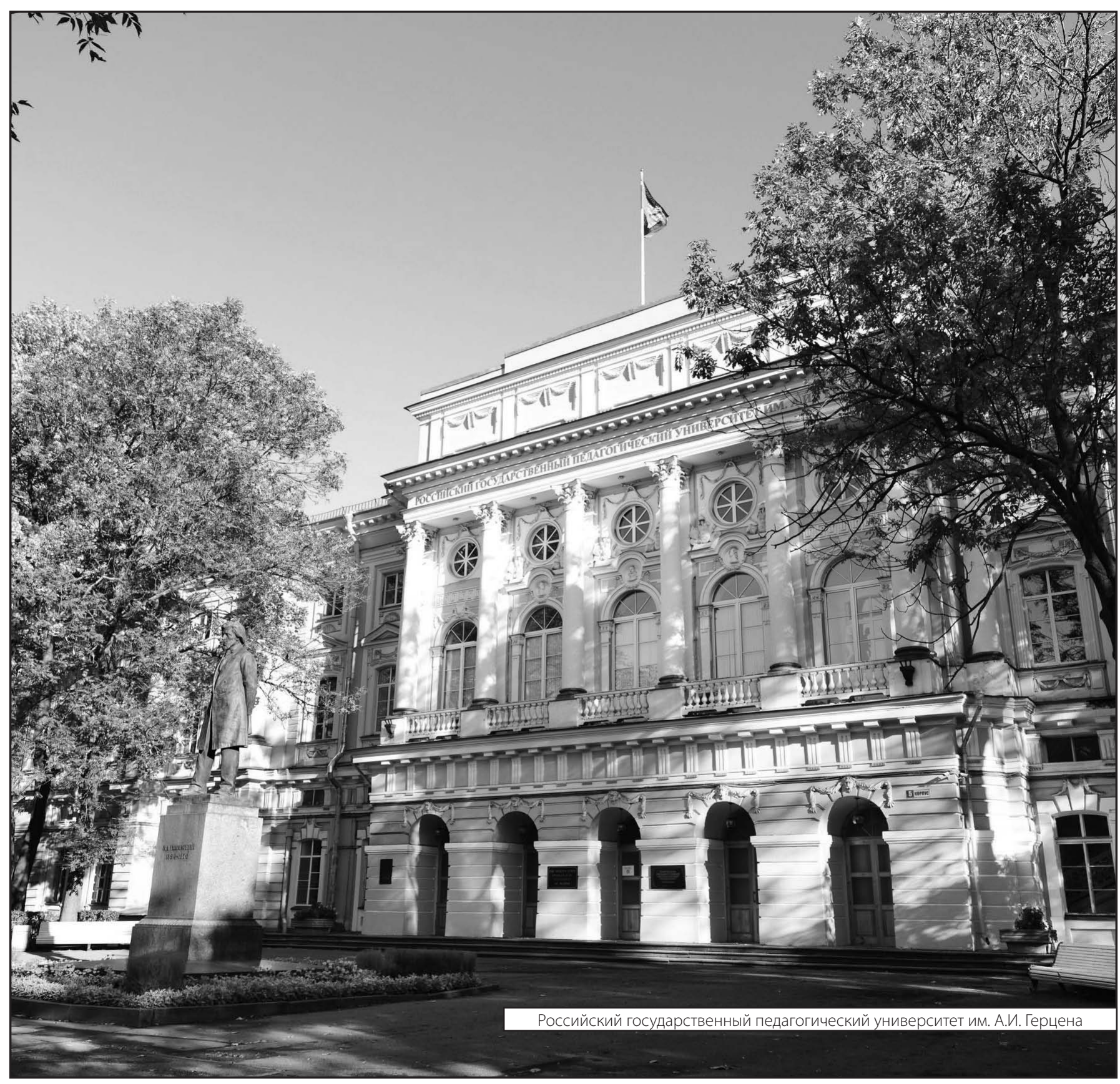

